\title{
Bipedalismo: uma breve revisão deste fator que distancia o ser humano dos demais primatas
}

\author{
Jane Daniele Jornada de Lima \\ Instituto Federal de Educação, Ciência e Tecnologia Farroupilha \\ (janejornada@hotmail.com) \\ Tanise Marian Gaike \\ Instituto Federal de Educação, Ciência e Tecnologia Farroupilha \\ (tata.gaike2@gmail.com) \\ Luciane Ayres-Peres \\ Instituto Federal de Educação, Ciência e Tecnologia Farroupilha \\ (luciane.peres@iffarroupilha.edu.br)
}

\begin{abstract}
Resumo: A evolução humana teve episódios durante sua trajetória que se estende desde o longínquo período em que os primeiros hominídeos ainda dividiam espaço sobre as árvores com seus parentes primatas. Os hominídeos desenvolveram um sistema de locomoção que os distanciou de seus parentes, sendo que este passou a ampliar seu horizonte ao se equilibrar sobre apenas dois dos membros. Neste artigo, o objetivo foi apresentar conexões entre distintas teorias sobre o bipedalismo, produzindo uma visão didática e concisa deste processo. Para tal, foi realizada uma revisão bibliográfica abordando as principais teorias sobre o tema. Estudos apontam alguns fatores, como: a diminuição de pilosidade, alteração do ambiente onde estavam inseridos, ou ainda se referem a um método de otimização energética. Após a revisão, fica possibilitada a análise didática de que o bipedalismo humano apresenta um processo complexo, do qual, distintos fatores foram decisivos para condicionar o andar ereto; entende-se, ainda, que esse processo não se deu de forma estanque, com cada mudança condicionada de forma isolada, mas ocorreu como reflexo de uma interrelação de fatores por milhares de anos.
\end{abstract}

Palavras-chave: Evolução Humana, Hominídeos, Pelos.

\section{Bipedalism: a brief review of this factor that distances human being from the other primates}

\begin{abstract}
The human evolution had several events throughout its trajectory, which extends from the distant period in which the first hominids still shared spaces among trees with their primate relatives. The hominids developed a locomotive system that put distances from their relatives, being that they started to get their horizons wide when poised just in two lower members. In this article, the aim was to show the connections among different theories about bipedalism, producing a didactic view and terse of this process. As such, it was carried out a bibliographic review approaching the main theories about bipedalism. Studies indicate different factors for that change, such as the decreased hairiness, changes in the environment in which they lived, and a method of energetic optimization. After this review it is possible to analyze didactically that the human bipedalism shows a complex process in which different factors were decisive to determine the erect walk, it is understood yet that process was not tight with each change made in an isolated way, but, it happened like reflex of an inter-relationship of factors for million years.
\end{abstract}

Keywords: Evolution, Hominids, Bristle. 


\section{INTRODUÇÃO}

A evolução dos seres vivos é um dos objetos de pesquisa mais abordados ao redor do mundo. $O$ entendimento dos processos de diferenciação das espécies está constantemente sendo revisitado, de modo que a busca por descobertas sobre as espécies, como surgiram às adaptações e, principalmente, quais foram os elementos que contribuíram ou condicionaram tais mudanças são frequentes. Fator preponderante na condição evolutiva da espécie humana, o bipedalismo, característica que diferencia o ser humano desde o surgimento do gênero Homo dos demais primatas, ainda causa debate, uma vez que cada vertente de pensamento aponta um ou mais elementos para a condição ereta e bípede do ser humano.

O livro "O Macaco Nu", de Morris (2004), tem por característica aproximar a conduta humana à dos demais primatas, principalmente símios, de modo que, ao apresentar o homem como um primata bípede glabro, remete à similitude com os nossos primos próximos. O autor qualifica a destreza de locomoção sobre dois membros e a condiciona ao fato da necessidade de utilização dos membros superiores em tarefas distintas.

Amaral (2014) associa, assim como Morris (2004), o bipedalismo a outra característica latente de diferenciação do Homo sapiens Linnaeus, 1758 dos demais primatas. Segundo essa autora: "Os primatas carregam suas crias agarradas nos pelos da mãe. Nós não temos pelos para os filhos se agarrarem, e, portanto, a única saída é carregarmos nossos filhos nos braços, o que exige que sejamos bípedes" (AMARAL, 2014, p. 03).

Da mesma forma, para Lovejoy (1981), a locomoção sobre as duas pernas liberou os braços para carregar crianças e objetos. Por outro lado, Hunt (1994), postulou que o bipedalismo emergiu como uma postura de alimentação, por ter permitido o acesso a alimentos que antes estavam fora de alcance. Já Wheeler (1992) acrescentou que, ao se erguerem, os antigos hominídeos puderam regular melhor as temperaturas corporais, expondo menos o corpo ao calor abrasador africano. Ainda neste contexto, Leonard (2003) sugere que o bipedalismo desenvolveu-se em nossos ancestrais, pelo menos em parte, por ser menos dispendioso energeticamente que o deslocamento sobre quatro membros.

A literatura, conforme apresentada, vislumbra condicionantes para o bipedalismo dos hominídeos, sendo consenso que foi o andar bípede que definiu a 
linhagem dos hominídeos graças às vantagens associadas a essa condição e apesar dos custos que essa situação trouxe à vida humana (LOVEJOY, 1981; WHEELER, 1992; MORRIS, 2004; STANFORD, 2004). É nesta dissonância de vertentes que se apresenta o olhar sobre o processo evolutivo que coloca o ser humano como único representante dos primatas a se firmar apenas sobre os membros inferiores. Dessa forma, o objetivo do presente estudo foi realizar uma breve revisão bibliográfica e apresentar conexões entre as distintas teorias sobre o bipedalismo, produzindo uma visão didática e concisa deste processo.

\section{REVISÃO}

No presente estudo foram apresentadas, por meio de uma breve revisão bibliográfica, diferentes vertentes sobre a origem do bipedalismo, observadas ao longo do século $X X$, a fim de compreender como o ser humano tem, nos dias atuais, a característica bípede como uma vantagem competitiva.

\subsection{Somos bípedes para buscar alimentos}

A alimentação dos primeiros hominídeos tinha uma base herbívora, sendo sensato associar à essa dieta o fato de que os mesmos hominídeos tinham sua locomoção obtida através de quatro apoios e tinham uma visão extremamente restrita ao solo e à altura de pequenos arbustos, de modo que os alimentos, que estavam ao seu alcance, eram provenientes de pequenos arbustos das savanas ou até mesmo estavam no solo, sendo essa a matriz energética de nossos parentes distantes. Há de se destacar que essa dieta herbívora também se associa à falta de condições favoráveis a caça, pois os hominídeos tinham locomoção dificultada por sua condição quadrúpede, e uma considerável diferença física em relação às suas possíveis presas, as quais eram extremamente fortes e robustas (MACHADO, 2004).

Nesta lógica de ampliação do campo de visão, encontra-se a teoria da vigilância de Dart (1925, apud DIEFENTHAELER, 2013), o qual destaca que, ao mudar do hábito arborícola para a vida terrestre, os hominídeos, ao ficarem em pé, seriam beneficiados com o aumento do seu campo de visão nas savanas africanas, observando sobre os arbustos e antevendo possíveis ataques de predadores, bem 
como ampliando sua capacidade de observação, seu senso de posicionamento e ainda possibilitando o alcance de alimentos que outrora não eram percebidos.

Hunt (1994) destacou que o bipedalismo permitiu aos antecessores primatas o alcance de alimentos que outrora eram de difícil acesso, como frutas ou brotos altos, uma vez que, antes, se restringiam a raízes e demais vegetais duros. Também, ressalta o autor, que, embora esses hominídeos já consumissem proteínas animais, pela predação de pequenos roedores e insetos, o ser bípede teve facilitada sua busca proteica, com a possibilidade de articular novas estratégias de caça de pequenos mamíferos.

\title{
2.2. Bipedalismo como fator de reserva energética
}

Muitos são os estudos sobre da eficiência locomotora dos animais, de modo a quantificar qual dos métodos de deslocamento tem atendido a atividade com menor dispêndio de energia. Segundo Vaughan (2003), a locomoção é o translado do centro de gravidade ao longo de um caminho, requerendo o mínimo dispêndio de energia. Portanto, os indivíduos escolhem a velocidade de andar - o produto do comprimento do passo pela taxa de passos - com a intenção de minimizar a energia metabólica gasta por unidade de distância percorrida.

Diefenthaeler (2013) classifica:

\begin{abstract}
"A marcha humana é suave, com movimentos regulares e repetitivos, é um andar econômico. Se comparado com o andar dos chimpanzés, economiza-se $75 \%$ de energia. Animais arborícolas têm um gasto energético ainda maior na locomoção, se comparado aos animais terrestres, pois precisam desafiar a gravidade ao escalar". (DIEFENTHAELER, 2013, p. 39)
\end{abstract}

A hipótese da eficiência energética também é defendida pelos antropólogos Rodman e McHenry (1980), que destacam que, em um contexto de mudanças significativas nas condições ambientais, com a redução das florestas e, consequentemente, das ofertas de recursos alimentares, o caminhar bípede e os braços livres resultaram em vantagem energética. Ao ficar ereto, foi possível alcançar alimentos de forma facilitada, inclusive os que estavam localizados em galhos antes inacessíveis.

Leonard (2003) corrobora a relação da eficiência energética do andar bípede.

"Análises dos custos de energia do movimento em animais demonstraram que, no geral, a maior demanda depende do peso do animal e da velocidade com que ele se desloca. $O$ mais 
surpreendente no movimento bipedal humano é que ele é notadamente mais econômico que o deslocamento quadrupedal em velocidade de marcha (LEONARD, 2003)".

\subsection{Viver nas savanas nos exigiu ficar eretos}

Considerando a ampliação das áreas de savana no continente natal da espécie humana (Continente Africano), destacando, nesse ambiente árido, as altas temperaturas, os primeiros hominídeos precisariam de alguma vantagem fisiológica para superar estas adversidades. Wheeler (1992) sugere em seus estudos que o hominídeo bípede apresentava vantagens termorregulatórias em relação ao préhominídeo quadrúpede, devido à redução da incidência de radiação solar direta e indireta e ao aumento da eficiência do mecanismo de sudorese, permitindo a dissipação do calor escaldante das savanas.

Para examinar a teoria que Wheeler propõe, pode-se imaginar uma savana, cujo clima seria muito inóspito para qualquer animal sem qualquer mecanismo de resfriamento. A maioria dos mamíferos de savana é equipada com Rete mirabile, uma rede de artérias finas na base do cérebro, juntamente com a circulação venosa do focinho (WHEELER, 1992). Isso permite que o cérebro possa esfriar rapidamente. No entanto, curiosamente, esse recurso está faltando nesses bípedes precoces. Assim, para Wheeler, os hominídeos utilizam-se de um sistema para resfriar seus corpos como um todo, refletindo em resfriamento do cérebro.

Ainda com relação a essa teoria, ao ficar ereto, o homem mantém os seus órgãos vitais distanciados do solo superaquecido da savana. Se ao andar em quatro apoios a distância média entre solo e tronco é inferior a $70 \mathrm{~cm}$, ao ficar ereto, a temperatura do solo afeta apenas as extremidades dos membros inferiores, e a radiação solar acaba também por influir em menor intensidade nos bípedes (WHEELER, 1992).

A termorregulação proposta por Wheeler (1992), também fora favorecida, segundo o próprio autor, por meio de mutações que culminaram com a redução massiva na quantidade de pelos corporais e o desenvolvimento de sistema de glândulas sudoríparas efetivas, de modo a permitir o controle térmico em ambientes de altas temperaturas. 


\subsection{Sem pelos, conduzimos nossas crias em nossos braços}

Para Lovejoy (1981), o bipedalismo tem uma razão biológica, qual seja, a necessidade dos hominídeos em utilizar os membros superiores, tendo seus braços e mãos livres. As mãos livres permitem ao indivíduo carregar alimentos e demais necessidades (como utensílios), sendo essa característica relevante na vida nômade, proposta por um ambiente em constante mudança. As mãos livres também auxiliam na proteção própria e dos demais membros de seu bando (LOVEJOY, 1981).

Amaral (2014) associa essa qualificação da liberdade dos membros superiores com a redução drástica dos pelos corporais dos hominídeos. Os primatas carregam suas crias agarradas nos pelos da mãe. Com a diminuição de pelos, os filhotes não têm no que se agarrar, portanto, a saída é as fêmeas carregarem seus filhos nos braços, o que exige o bipedalismo.

Conforme Amaral (1998), todos os primatas superiores, exceto os humanos, carregam as suas crias agarradas nos pelos do corpo de um familiar adulto, normalmente, a mãe, sendo que nos símios, pertencentes a nossa linhagem evolutiva, essa condução materna se prolonga por vários anos. Essa condução se dá de forma ventral para os primeiros momentos, e, nos anos seguintes, os filhotes passam para o dorso materno.

A mudança da locomoção quadrúpede para trípede ou mesmo bípede ocorre sistematicamente entre os grandes símios quando a segurança da cria requer suporte manual. Está claro que a segurança no processo de carregar as crias leva a mudanças de forma de locomoção, dependendo do peso das crias, da capacidade dos pelos e da pele em aguentar a tensão, e da capacidade preênsil das crias. Com a ausência dos pelos, os filhotes dos hominídeos não tinham como ficar suspensos, como no caso dos demais primatas, exigindo assim que os membros superiores fossem disponibilizados para a condução da cria (AMARAL, 1998; MORRIS, 2004).

A oportunidade da utilização dos membros superiores,quer seja para conduzir os filhotes em seus braços na ausência dos pelos firmes para que os mesmos possam ficar suspensos (AMARAL, 1998), quer seja na utilização dos membros para coleta, condução de alimentos, ou na utilização de ferramentas (LOVEJOY, 1981), só é possível na condição ereta. 


\section{DISCUSSÃO}

Os processos evolutivos são desencadeados mediante uma congregação de elementos endógenos e exógenos. Considerando as mudanças dos cenários ambientais experimentados pelos primeiros hominídeos, é de fácil percepção, que não só os hominídeos, mas todas as espécies tiveram que passar por um período de adaptação, sob pena de tornarem-se extintas. No caso dos hominídeos, as florestas densas deram lugar a extensas e quentes savanas, fato este que pode ser considerado a mola propulsora para evolução do bipedalismo em grupos de primatas, esses, até então arborícolas, que passaram a viver no solo quente e árido, subindo nas poucas árvores, apenas em busca de alimento ou de proteção (WHEELER, 1992).

As vertentes teóricas que visam explicar esse processo evolutivo que nos possibilita a vida bípede vão muito além das apresentadas, porém, é consenso que o andar bípede vertical é marco importante para a condição humana e uma das características definidoras que nos tornou humanos (DIEFENTHAELER, 2013).

A definição da causa basilar desencadeadora do processo de mudança do modo de locomoção fica comprometida, uma vez que, mesmo com os avanços da ciência, várias são as informações que se perderam no passar dos milênios. Fósseis delimitam com certa precisão, quando houve mudanças ósseas que auxiliaram no andar bípede, porém, não há uma definição se esse feito foi anterior à mudança cutânea, com a perda de pelos que transformaram esses primatas em "macacos nus" (DIEFENTHAELER, 2013).

O controle térmico possibilitado pela conduta ereta é de extrema relevância nas savanas africanas, porém, deve-se atentar que achados recentes sugerem que, mesmo antes da expansão das savanas, alguns antropoides extintos, possivelmente precursores do gênero Homo, já eram bípedes ou estavam a caminho disto (STANFORD, 2004). Deve-se aqui também perceber que o andar ereto demonstrou um ganho significativo na eficiência energética dos organismos. Se os recursos diminuem, existe a necessidade de otimizar a utilização da energia, para um modo mais efetivo de locomoção.

Stanford (2004) atribuiu o bipedalismo a diversos fatores, desde a mudança da condição alimentar, passando o hominídeo a buscar alimento através da caça e da coleta, até a necessidade de aplacar distúrbios coletivos, quando ficar em pé era 
necessário para parecer incisivamente convincente. Ao ficar em pé, foi possível estabelecer vantagem competitiva em relação aos demais primatas. Foi ampliado o horizonte, a visão e a percepção do espaço que o cercava, fato esse utilizado para proteção, permitindo ampliar a condição de defesa contra possíveis ataques, bem como tornar-se caçador que, ao fazer uso da condição ereta associada à utilização dos membros superiores para empunhar ferramentas, nos possibilitou figurar não mais como presa, mas como predador.

\section{CONCLUSÃO}

Independente da abordagem que for utilizada, quando se buscam delimitar questões evolutivas, inúmeros são os fatores que vêm à tona. Isso porque os fatos não se consolidam em um curto espaço de tempo, mas ao longo de milênios, e normalmente não se referem a uma única alteração gênica e sim a um rearranjo estrutural complexo.

O andar bípede que hoje nos difere dos demais primatas é reflexo de mudanças fisiológicas que não foram consolidadas em uma geração, mas sim, são reflexo de um constante processo evolutivo, que hoje permite que a espécie humana se mostre dominante sobre os demais seres, possuindo alto grau de desenvolvimento, impondo-se ao meio e às demais espécies, tanto por sua capacidade intelectual quanto pela habilidade com seus membros superiores desenvolvidas a partir da postura ereta.

Assim como se entende que o processo de transformação do andar sobre quatro apoios para uma conduta ereta bípede não parte de uma mudança fisiológica simples, é salutar entender que a mesma mudança não é reflexo de uma situação isolada, mas sim, da congregação de fatores externos e internos que condicionaram essa transformação para a perpetuação e continuidade da espécie.

Todas as hipóteses consideradas não se revelam como excludentes, e sim observam um condicionante específico. Se considerarmos o aquecimento do ambiente e a redução das florestas, poderia se apreciar a hipótese de regulação térmica defendida por Wheeler (1992), mas para tanto, não necessariamente deveríamos afastar a hipótese de eficiência energética para a marcha bípede defendida por Rodman e McHenry (1980), nem a questão abordada por Amaral 
(1998), associada à necessidade do hominídeo em liberar seus braços para os outros afazeres.

Frente a todas as considerações apontadas por diferentes pesquisas antropológicas, no que se refere à origem do bipedalismo, atrelado à falta de precisão para se determinar com exatidão uma cronologia dos fatos - ausência de pelos $x$ andar bípede $x$ mudança de ambiente, florestas densas para savanas - e ainda considerando o processo de seleção natural, não nos resta senão interpretar o andar bípede humano como reflexo adaptativo condicionado a múltiplos fatores.

Assim, conforme determinadas ações se mostravam vantajosas, como o fato de desenvolver os membros superiores para atividades mais complexas ou a redução drásticas dos pelos, ou o caminhar ereto, com economia de energia, essa característica se sobrepunha às outras de modo que o bipedalismo se consolida pela sua efetividade, no trato com as dificuldades propostas pelo meio à consolidação das espécies. As diferentes vertentes observadas, em sua maioria, não são excludentes, de modo que, para a apresentação didática desse importante avanço evolutivo do ser humano, deve-se buscar olhares amplos, considerando-se todas as mudanças envolvidas e propostas, lembrando que o bipedalismo não se deu de forma instantânea, mas sim, durante um longo período evolutivo.

\section{REFERÊNCIAS}

AMARAL, L. Q. Mechanical analysis of infant carrying in hominoids. Naturwissenschaften, 95 (4): 281-292. 1998.

AMARAL, L. Q. Bipedalismo: solução para carregar crias, correlacionada com a redução de pelos. Revista da Biologia, 11(1): 19-27. 2014. DOI: 10.7594/revbio. 11.01.04.

DIEFENTHAELER, I. B. F. Das árvores às panelas no fogo: Como nos tornamos humanos. Faculdade de Medicina/UFRGS, Porto Alegre, Trabalho de Conclusão de Curso de Graduação no Curso de Nutrição, 2013. 132 p.

HUNT, K. D. The evolution of human bipedality: ecology and functional morphology. Jornal of Human Evolution, 26: 183-202. 1994.

LEONARD, W. R. Alimentos e a evolução humana. Mudança alimentar foi a força básica para sofisticação física e social. Revista Scientific American Brasil Especial. 8 ed: São Paulo, 2003.

LOVEJOY, C. O. The origin of men. Science, 211 (4480): 341-350. 1981. 
MACHADO, J. De Herbívoros a Carnívoros - A alimentação nos primórdios da Pré-história. Revista digital Planeta Educação, 2004. Acesso em 24/11/2016. Disponível em: http://www.planetaeducacao.com.br/portal/artigo. asp?artigo $=179$.

MORRIS, D. O Macaco Nu. 15 ed. Rio de Janeiro: Record, 2004. 270p.

RODMAN, P. S., McHENRY, H. M. Bioenergetics and the origin of hominid bipedalism. American Journal of Physical Anthropology, 52: 103-106. 1980.

STANFORD, C. Como nos tornamos Humanos: Um estudo da evolução da espécie humana. Rio de Janeiro: Campus, 2004. 232p.

VAUGHAN, C. L. Theories of bipedal walking: an odyssey. Journal of Biomechanics, 36 (4): 513-523, 2003.

WHEELER, P. E. The influence of the loss of functional body hair on the water budget of early hominids. Journal of Human Evolution, 23: 379-388. 1992. 